\title{
Exploring STEM Undergraduate Self-Regulated Learning at a \\ Vietnamese Transnational University
}

Christina W. Yao ${ }^{1 *}$, Trentee Bush ${ }^{2}$, Courtney Collins ${ }^{3}$, Minerva Tuliao ${ }^{4}$, Kaleb L. Briscoe ${ }^{5}$ and Ngoc Lan Thi

\author{
Dang ${ }^{6}$ \\ ${ }^{1}$ University of South Carolina, USA \\ ${ }^{2}$ Northeast Community College, USA \\ ${ }^{3}$ University of Nebraska-Lincoln, USA \\ ${ }^{4}$ Texas Tech University, USA \\ ${ }^{5}$ Mississippi State University, USA \\ ${ }^{6}$ Vietnamese-German University, Vietnam \\ *Correspondence: CY9@mailbox.sc.edu
}

\begin{abstract}
STEM education in Vietnam is prioritized, yet effective learning may be difficult for students attending transnational universities. The purpose of this study is to examine the self-regulated learning experiences of STEM undergraduate students attending a collaborative transnational university in Vietnam. Challenges included English language instruction and STEM-specific terminology. Despite barriers to their learning, students describe strategies for navigating their learning process. Strategies included extensive rereading of the material, using Google to look up new terms/ideas or to translate words, asking instructors for translation, and reviewing online resources. Implications for practice include instructors providing more detailed feedback and guidance and leveraging technology use for learning.
\end{abstract}

Keywords: Vietnam, transnational education, STEM, self-regulated learning, undergraduate students

\section{Introduction}

Vietnam is unique in that there is a high demand for higher education yet the government has a limited infrastructure to support the demand (Ashwill, 2006). As a result, the Vietnamese government has invested in the creation of "new model universities," using partnerships with foreign countries and institutions to supply the demand for quality higher education (World Bank, 2017). Part of the national Received April 18, 2020; revised July 19, 2020; September 19, 2020; accepted September 26, 2020; electronically published March 2, 2021 
strategy places an emphasis in producing skilled workers to contribute to the country's economy as a way to increase skills, particularly in science, technology, engineering, and maths (STEM) fields. As a result, STEM education is prioritized because of the belief that STEM training and education can develop high-quality human resources for Vietnam through the K-12 to higher education pipeline (Nguyen \& Dang, 2019).

Effective STEM education is critical, as various factors influence the experiences of undergraduate STEM majors. For instance, lectures tend to be less successful means for students to obtain STEM material than active learning (Freeman et al., 2014; Smith et al., 2014) while selfmotivation and institutional policies can play a role in a student's ability to keep moving forward (Cromley et al., 2016). In addition, various achievement gaps are often noted for minoritized groups in the STEM fields (Gonzalez \& Kuenzi, 2012). Each of these challenges makes STEM education seemingly more difficult for students to gain and maintain interest in the STEM fields of study.

Another major factor in learning can be the language barriers between scientific community and the language of instruction. This scientific language, often full of English-based scientific jargon, can make it difficult for learners to translate and communicate across cultural barriers. In some cases, it might even lead to cultural identity conflict (Hwang, 2013). For students at transnational universities in Vietnam, they face the additional challenges of instruction conducted completely in English and considerable teaching by short-term foreign faculty. Despite the difficulties, Vietnamese students choose to attend transnational universities because of perceived benefits of English language instruction and low cost for an international degree (Yao \& Garcia, 2018). Thus, understanding factors that contribute to undergraduate student learning in STEM will illuminate the classroom needs of students at transnational institutions. The purpose of this study is to examine the self-regulated learning experiences of STEM undergraduate students attending a collaborative transnational university in Vietnam. We seek to answer the question, "How do STEM undergraduate students engage in selfregulated learning at a Vietnamese transnational university?"

\section{Student Learning in Vietnam}

Vietnam is attempting to reach a global higher education standard (Nguyen, 2011), especially in STEM fields. Students proficient in STEM fields demonstrate strengths such as developing creative and logical thinking, possessing outstanding learning and working capacities, and being able to develop soft skills more. As a result, the Vietnamese Ministry of Education and Training (MOET) is now attempting to develop the curriculum of high schools and organizing teaching activities and methods in accordance with STEM contents (Nguyen \& Dang, 2019). 
The emphasis on STEM education has also permeated the higher education sector in Vietnam. The Vietnamese government has expanded higher education offerings in the past 20 years, resulting in a massification of higher education providers to meet the demands of students (Dao, 2015). Part of the strategy for improving higher education outcomes includes an emphasis in producing skilled workers to contribute to the country's economy. However, skills from recent graduates are not matching the needs of the developing science and technology economy. Transnational universities, all of which partner with foreign countries such as Germany, France, and Japan, play a critical role in developing the skills of the future workforce in STEM. These transnational universities conduct instruction in English, seek to use active learning strategies, and employ foreign faculty for teaching (Yao \& Collins, 2018).

There has been little scholarship that specifically examines the benefits or challenges to the use of English in transnational STEM classrooms. Mazak and Herbas-Donoso (2014) discussed STEM learning in multilingual contexts and found that "there is nothing inherently scientific about English that should favor it over the use of any other language" (p. 30). According to Wilkins and Urbanovic (2014), TNHE use of English as a lingua franca is more pervasive due to "wide[ly] held assumption" (p. 2) that the only way to legitimize TNHE programs is to teach in English. Yet, some institutions opted to utilize host/partner nation language instruction due to concerns regarding quality of instruction due to a lack of proficiency at the university level by both student and faculty (Wilkins \& Urbanovic, 2014). However, TNHE institutions not using English language instruction will require "a clear rationale and benefit to students of studying in a language other than English" (Wilkins \& Urbanovic, 2014, p. 13) in order to be successful. This rationale is challenged by the fact that English is being pervasively deemed the "language of science" (Mazak \& Herbas-Donoso, 2014) in contexts that find educators and students utilizing translanguaging and code-switching (Bahous et al., 2014) to implement curricula. According to Mazak and Herbas-Donoso (2014), translanguaging is used when multi-lingual speakers use multiple languages to communicate in complex multi-lingual contexts. Code-switching is the practice of multilingual speakers switching between multiple languages in a spoken context. For education this may include a lecture, or even a single statement by a student.

Practices of requiring and implementing English instruction on an institutional or national level may lead to difficulties in student learning. Yao, Garcia, and Collins (2019) found that the use of English as the operating language at transnational universities provided both challenges and opportunities for student learning. Challenges included the use of technical jargon and difficulties communicating with faculty. However, students used strategies such as collaborative learning and supplemental resources to navigate the English language barriers (Yao \& Collins, 2018; Yao et al., 2019). Yet despite challenges, 
Vietnamese students viewed English language development as a way to contribute to their employability post-graduation (Yao \& Tuliao, 2019).

\section{Conceptual Framework: Self-Regulated Learning}

Self-regulated learning was used as a framework to understand the way students responded to the challenges of what they perceived as a barrier to learning STEM concepts within an English-instruction context. As a meta-construct, self-regulated learning is defined as a process whereby learners actively set learning goals, and flexibly guide and monitor their cognition, motivation, and behaviors within learning contexts to ensure success (Singer \& Bashir, 1999; Pintrich, 2000). Students are described to be selfregulated if they are meta-cognitively, motivationally, and behaviorally active participants in their own learning process (Zimmerman, 1989). Prominent models of self-regulated learning (e.g., Zimmerman, 1989; Pintrich, 2000) focus on how cognition, meta-cognition, motivation, and context affect the learning process (Saks \&Leijen, 2014). Specifically, Zimmerman (1989) considered three common components that existed across most self-regulated learning perspectives: 1) purposeful learning strategies used by students to improve academic achievement, 2) self-monitoring and feedbacking of both own performance and strategy effectiveness, and 3) motivational and self-efficacy beliefs that result from, or are influenced by, the type of self-regulatory strategy or response in a socio-environmental context.

In higher education contexts, self-regulated learning offers a way to understand individual differences in learning among students, including diverse strategies in delivering modes of learning, such as the use of technology (Cassidy, 2011). Previous research in educational contexts provide guidance on the implementation of self-regulated learning, including the creation of enabling environments that foster students' learning strategy development with growing emphasis on technology as a tool for selfregulated learning and positive self-efficacy in goal achievement (Cassidy, 2011). Additionally, Lin (2019) studied self-regulated learning strategies among international and ESL college students majoring in both STEM and non-STEM fields. She found that these students were motivated to learn specific and advanced knowledge and skills. When they try to avoid making learning mistakes, it demotivates them to using deeper self-regulated learning strategies. The socio-environmental context was also significant. Students try hard to succeed because failure is seen as a financial and social disappointment for their families back home, and students who are found to be more competitive than their peers were willing to study with classmates more often.

\section{Methods}

We utilized a single case study methodological approach for this study. Single case study research is most applicable when a researcher is interested in studying one thing or group (Stake, 1995). 
Additionally, single case studies allow researchers to question existing and new theoretical relationships, which provides a deeper understanding of the case. While we were most interested in hearing about student experiences and how they may offer insight into the STEM learning experiences at a Vietnamese transnational university, the institution's context played a significant role in shaping the research design of this study. Therefore, the institution served as the case, using Vietnam Transnational University (VTU) as a pseudonym. Students were our units of analysis as they provided perspectives on what factors contribute to their STEM learning at a collaborative transnational university. The findings from this current study are from a larger study in which we questioned how students engage in the learning process at collaborative transnational universities in Vietnam, which included graduate students in social sciences and STEM.

\section{Insitutional Context}

To understand the institutional context of our site, we collected institutional data by conducting a keyword search and selection of documents from the college's websites. We specifically reviewed the institutional websites to provide an understanding of how VTU supports students learning within STEM. This data was then analyzed following Bowen's (2009) recommendations for document analysis.VTU is public university established in Hanoi, Vietnam in 2009, and collaboratively funded by both the Vietnamese and the French government. VTU offers eight bachelor's degrees, which follows the European model of three years for graduation. Courses are taught primarily by short-term French instructors who "fly in" to teach two week courses. The mission of VTU is "to provide high quality human resource in Science and Technology serving for the development of research and technology transfer, for the demand of socio - economic development of Vietnam and at the same time making all efforts to become an excellent research-oriented University in Vietnam, reaching the regional and international standards."

\section{Data Sources}

Selection of participants was a result of purposeful sampling. Purposeful sampling strategies are "based on the assumption that the investigator wants to discover, understand, and gain insight and therefore must select a sample from which the most can be learned" (Merriam \& Tisdell, 2016, p. 96). Recruitment emails were sent to eligible participants, which included all current students enrolled at VTU. Semi-structured interviews were conducted in person with ten undergraduate students at VTU. Using semi-structured interviews provided the opportunity to ask follow-up or clarifying questions related to participants' specific and unique experiences in their respective graduate program (Glesne, 2010). Participants were able to share thoughts on their specific graduate programs, including feedback 
on faculty and their motivation to attend VTU. All communications, including solicitation emails, interviews, and consent materials, were all conducted in English. Because English was not participants' primary language, the interviewers ensured ample time for participants to review printed consent forms and would clarify any unfamiliar terms. In addition, during interviews, interviewers took care to avoid the use of jargon and allow time for reflection.

Four of the participants identified as women, and the representation of grade level included first year (3), second year (3), and third year (4) students. Each interview lasted approximately 60 minutes and was conducted in English. Interviewing participants was the most appropriate mode of inquiry because it helped us learn about their experiences and allowed for their lived experiences to emerge (Charmaz, 2001). As a result of our participants' broad range of interests and experiences, we have been able to collect rich data, which has increased the trustworthiness of the data collected (Glesne, 2010).

Gathered data from each individual interview was organized and transcribed on an ongoing basis, including details on dates, pseudonyms, and any other notes that the first author took during and after the interviews. Examples of interview questions include: "Tell me what you were looking for in a university prior to starting in your current program" and "What do you think are the benefits of attending VTU instead of another university in Vietnam?" Although the researcher had some predetermined interview questions, she allowed for conversation to emerge naturally and asked follow-up questions when appropriate.

Participants were encouraged to select their own pseudonyms to be used instead of their real names. The decision to do so with this study comes from the research group's belief that the designation of pseudonyms is a discreet form of power exertion (Guenter, 2009). Often in international research, the selection of pseudonyms anglicizes or indirectly removes the cultural identity of participants (Kvale, 1996), which the researchers sought to avoid throughout the interview process.

\section{Data Analysis}

Coding and analysis was conducted by a team of researchers after the first author returned to the United States. When coding, we made categories that were based on the research questions and conceptual framework from which we interpreted emerging themes (Rossman \& Rallis, 2003). We utilized deductive coding, which includes a "start list" (Miles et. al., 2014, p. 81) based on this study's interview protocol and conceptual framework. We first searched for broad categories and then developed themes that emerged from the participants' experiences. Themes were coded by identifying appropriate phrases that related to our themes. 
After concluding first cycle coding, we moved on to second cycle coding, which is "a way of grouping those summaries into a smaller number of categories, themes, or constructs" (Miles et. al., 2014, p. 86). We organized the first cycle codes by clustering them under common themes or patterns that emerged from the interviews. This was an iterative process of reflecting and clustering codes into code categories. We continuously refined the pattern codes until we felt the final codes were representative of the participants' experiences.

\section{Findings}

Participants shared their experiences that were distilled down to two specific themes related to learning and engagement: the simultaneous navigation of English language and STEM concepts and strategies for learning at transnational universities. Participants shared their experiences with using English in their STEM classrooms. For many of the participants, English had been learned at a young age, generally around grade three. Their English skills were developed enough to meet the required basic English skills for admittance at their university. Typically, the reading and writing of English are tested while speaking and comprehension of English were not included in the tests.

\section{Challenges of Undergraduate STEM Education At a Transnational University}

Students often noted challenges in the classroom with their English, whether it be from instructors lack of English proficiency or from their own translation challenges. Gia shared, "At first, I can still understand them. I just find it really uncomfy to hear them pronouncing words incorrectly, and it's quite frustrating at first, but then I just try to push it apart, ignore it and focus on the important things." Duong provided more insights on his own translation challenges, stating,

So, the slide English, and the teacher also recommend some textbook in English. So we have to learn by this textbook. And some course the teacher also suggest us to learn from the online course. So we have to listen to that course. And many subject in university, we have to do the work because the presentation, and it is only in English, so we have to learn this for presentation.

Many participants described their challenges with utilizing English in courses that were STEMheavy in topics. For example, Hat, a third-year Pharmacological, Medical and Agronomical Biotechnology (PMAB) major, summed up the difficulties, saying, "To be an English environment with little my own language here, that is challenging. I know this also a barrier to learning science, because we had a double barrier." This additional language of scientific or mathematic terms was challenging for the participants. In addition to the language challenges, the university emphasized a STEM culture that was new to many participants. Ghoster shared with us that the focus was on science when he said, "So I'd say this is a science university, science college, so it focus more on knowledge about the science than language." 
Ghoster, a second-year student in Space and Applications (SA), described his professor who "used to say when you study science, no matter about the English, it also kind of language," which illustrates the complexities of learning science. Sherlock, a second-year student in Renewable Energy (RE), similarly found challenges in his STEM classes. He stated that "in courses, there's a lot of new terminology" and as a result, he "need to start to be familiar with the new terminology in the class so that I can maybe overcome it easier," but the intersection of learning new terms as a non-native English speaker proved to be difficult in classes.

Zimy, a first-year biology major, shared the reality of this barrier:

Sometime our student here think that, said that how English has destroyed their science dream because it's very hard to translate back and back to English again. And the teacher in our school try as much as they can to reduce. They try to explain every word in English so we don't have to translate it into Vietnamese.

Repetition of the learning challenges was noted. Most participants, even those who felt more proficient with English, found this simultaneous navigation of language to be difficult. For some other students, their studies at this transnational university were their first real venture into the English language. Naly, a second-year Advanced Materials Science and Nanotechnology (AMSN) major, was asked what her biggest challenge was at her university. Her biggest challenge was using English in the classroom because "I just study it last year. I do not focus on it when I was young, so now I have to study and I feel that this is hard." Thus, in addition to learning new content in classes, Naly had to navigate the complexities of language.

Participants also struggled with the timeline involved in the course structure at the transnational university. Many courses are shorted in terms of length of time and the material is taught in a very intense format. Hat shared that one of his courses was only one week long. In his opinion, "It's too short. We would like to extend it to two weeks, maybe they can convey all the knowledge to us in such a longer span of time." This challenge arises for the transnational university when faculty from the partner countries fly in to serve as lecturers for a short period of time. Sally, a third year Advanced Material Science and Nanotechnology student, shared her thoughts on the difficulties "to learn all, everything, in one week and then do the exam. However, for us, our lecturer said that we can do all the course in one week but if we have further answer, just give her an email."

\section{Strategies for Self-Learning to Overcome Challenges in STEM}

Ghoster described his process for understanding his professors' lectures at home when he has difficulty with comprehension while in class. He "just take key words and I re-skim at home. It's kind of way to understand the lecture. I'm not able to understand the words the teachers say when I in class so I 
see the keyword and I read the slide at home." This process, as reported by Ghoster, takes a lot of time and interestingly, he would learn new words but not be able to translate them into his own native language. "I know the words mean something, but I don't in Vietnamese," which may prove to be difficult with future application.

Many participants described the importance of technology in their learning experiences. As Larry, a first-year student in PMAB, matter-of-factly stated, "everybody Googles." This sentiment was repeated by almost every participant in this study. Larry would study on his own and while writing papers, he "sometimes to the internet and find some picture to help" so that way, he "can understand this more." Another example of using the internet included Hat, who utilized Google because he found that "it is not interesting to have to hear lecturers talking all the time in class." Rather, he found much benefit by going online and finding "many different alternatives." He was able to search for and find lecture videos, which allowed him to be "exposed to new ideas." He spoke extensively on the benefits of viewing outside sources on his learning. Link Noisyboy, a third-year biotechnology major, said

I can research, I can talk with, I can chat with my teacher and I will learn, I will read articles many times. In the first time, I maybe cannot understand what the article say when we learn what we learn when we read the article many times and we can understand and understand the word, one by one.

In essence, these participants had created their own learning strategies for a complex issue. These strategies could be boiled down to: extensive rereading of the material, using Google to look up new terms/ideas or to translate words, asking the Vietnamese instructors for a translation, listening to online courses, and more. Students at this university had not only recognized their largest challenge, but had adapted to overcome it. They had a vested interest in doing so as many of them had globalized career goals in STEM industries.

\section{Discussion and Implications for Practice}

The students in this current study have a variety of language barriers to overcome in order to have a successful educational outcome. These barriers include the traditional challenges related to learning in a second, non-native language. In addition, this study has provided the researchers with some insight into the challenges these students are facing as they must also learn and navigate the nuances of the languages of science and mathematics. Knowing that STEM terms have their own universal meanings and applications, these transnational students have expressed that STEM is like an additional language they must learn to speak and understand, which is reflected in Mazak and HerbasDonoso's (2014) study. 
Students referred to the English language as an additional learning barrier in addition to the STEM jargon, specifically as something they had to overcome in order to be successful students. This unforeseen obstacle was noted by several students and became a theme among this population of transnational students which was reflected in previous studies (Yao \& Collins, 2018; Yao et al., 2019; Yao \& Tuliao, 2019). Many of the students self-taught STEM terms through personal research or contextual cues. They used whatever resources they could gather to make sense of the STEM terms not just in English, but also translated into their native language to have a stronger sense of the meaning. Their goto method was often Google, but they used images, videos, and text to help make the connections. The course materials were often read multiple times, and occasionally the instructors were directly asked for the translations to these STEM terms. Overall, students moved beyond relying on lectures for learning the nuances of course material, as demonstrated in previous studies on STEM learning (Freeman et al., 2014; Smith et al., 2014).

The challenges with learning were not viewed by the students as roadblocks, but simply as acknowledgments to their transnational system of learning. They recognized that STEM terms were universal and did their best to understand them in both languages. However, this part of their education was very much a self-taught concept, including the use of self-monitoring and motivation for academic achievement (Zimmerman, 1989). Because instructors did not appear to emphasize teaching these STEM terms as part of the classroom material, a great majority of overcoming the learning challenges was performed outside the classroom. The use of technology greatly assisted students in their self-regulated learning (Cassidy, 2011) as evidenced by the use of Google and other online resources.

STEM education has gained attention on an international level, yet rarely is the role of language discussed in student learning. More importantly, there is limited attention between the intersection of learning a new scientific language and students' non-native language of English. Thus, this study contributes to understanding how transnational universities can foster student learning and engagement in STEM courses, particularly at the intersection of navigating multiple languages and contexts. Although situated at a single site in Vietnam, this particular study may be used as a foundation for further studies on transnational STEM universities in Southeast Asia, after careful consideration of contextual and cultural differences. Thus, understanding factors that contribute to undergraduate student learning in STEM will illuminate the classroom needs of students at many transnational institutions.

This research provides valuable insights on the learning barriers that exist for undergraduate STEM students learning at a Vietnamese transnational university. In connection with self-regulated 
learning (Zimmerman, 1989), potential implications for this study include engaging learning through strategies that strengthen students' proficiency in English, providing essential feedback that build students' performance, and incorporating technological savvy strategies and modes of learning into the curriculum. Despite English being a requirement for entry into transnational universities, many students struggle with aspects of English (e.g., writing, reading, and/or speaking) once in the classrooms. Although some instructors recognize the language barriers that exist, instructors need to develop tangible strategies to ensure that students are able to learn and navigate these complex barriers inside of the classroom. This should include providing students with tips and resources that can be incorporated into their study regimen at home.

Balancing learning English and STEM concepts can also be extremely difficult for students at transnational universities. Our participants described how they often had to juggle learning STEM concepts and English with little to no assistance. While students taking initiative to gain skills in English and STEM is important, due to the nature and swiftness of transnational education, faculty members should also consider how they can make learning English and STEM concepts more plausible. This can include providing students with detailed feedback on assignments, projects, and group work to ensure that they have a clear understanding of course concepts. Instructors should also consider the ways in which they can provide encouragement to students who are struggling with English and STEM concepts. This could include simple things such as encouraging and praising students who make progress throughout the course.

Technology, such as the internet, was an extremely beneficial learning tool for our participants. Several participants referenced how they found alternative lectures and videos that helped them understand course materials. Because technology was so important to many of our participants learning experience, our recommendation is that transnational universities and instructors find innovative ways to incorporate technology into classroom learning. Overall, the development of technology in the classroom by creating videos and online lectures would assist students who may have challenges grasping course materials and jargon.

\section{Limitations and Recommendations for Future Research}

There are a few limitations associated with this research that future studies of similar topics should consider and address. First, the participants were contacted and located through emails, so only those responding were able to be selected for the study. Only ten students responded and agreed to participate in face-to-face interviews, which made the sample size rather small. Accordingly, future empirical studies of self-directed learning of STEM students should employ multiple sampling techniques 
in order to enlarge the sample size. In addition, researchers can select STEM students from a few more transnational universities in one country to enrich collected information and thus diversify research results. Also, comparative and international research on STEM students' self-directed learning can be conducted with data collected from transnational universities in two or three different countries in Southeast Asia.

Second, because the language used in the interviews was English, which is not interviewees' native language, some of them could not fully express their ideas due to the limitation of their foreign language proficiency. In this regard, this may adversely influence the reliability of the findings to a certain extent. Yet as a way to mitigate this limitation, we gave participants the opportunity to review their interview transcripts yet few chose to do so.

Third, the time spent on the research site was limited. Therefore, future researchers should spend more time on the field site to observe the participants' learning context and develop "trust and cooperation" (DeWalt \& DeWalt, 2002, p. 40). Perhaps an ethnographic study would elicit deeper meaning making of and by the participants. In doing so, we may receive additional nuances about the students' experiences.

\section{Author Note}

Christina W. Yao, Ph.D. is an Assistant Professor of Higher Education and Program Coordinator for the Higher Education and Student Affairs Master's program at the University of South Carolina. She is a qualitative researcher who primarily studies student engagement and learning in higher education. She operationalizes her research focus through three connected topical areas, including: international/comparative education, teaching and learning, and graduate education. Some current projects include a collaborative study on graduate students' international scholar-practitioner development, graduate student teaching and learning in Vietnam, and the college transition process for international students of Color.

Trentee Bush, Ph.D. is an Agriculture/Horticulture/Mathematics Instructor at Northeast Community College in Norfolk, Nebraska. Her primary research is focused on dual credit learning, specifically STEM courses. She is strongly engaged in community colleges and their unique educational challenges. Current research projects and grant proposals include transnational universities in Vietnam, Regenerative Agriculture, and Urban Agriculture/Horticulture. 
Courtney R Collins, Ed.D. is an Adjunct Faculty for Lesley University's International Higher Education Program and Civilian Training Instructor for the Department of Defense in Washington, D.C. She previously worked for the U.S. Department of State in Belgium and China managing the Fulbright and American Cultural Center programs, as well as in U.S. higher education as a program coordinator, student advisor, and admissions counselor. As a qualitative researcher, her focus has been on international student mobility in post-secondary education, transnational education in Vietnam, and student engagement.

Minerva D. Tuliao, Ph.D. is an Adjunct Faculty in the Department of Educational Psychology and Leadership, College of Education at Texas Tech University. She has 12 years of experience working in the private sector as a human resource and organization development practitioner. Her research and professional interests include implementation science, human resource development, immigrant/refugee employability and workforce transitions, community colleges, and culture-specific and mixed methods research.

Kaleb L. Briscoe, Ph.D. is a new Assistant Professor of Educational Leadership - Student Affairs and Higher Education at Mississippi State University. Her research agenda focuses on problematizes oppressed and marginalized populations within higher education through critical theoretical frameworks and qualitative methodological approaches. Through her scholarship on campus racial climate, she seeks to disrupt whiteness and white supremacy on predominantly white campuses. Her research shapes administrators, specifically university presidents' responses to race and racism, by challenging their use of anti-Blackness and non-performative rhetoric.

Ngoc Lan Thi Dang, Ph.D., is the Director of the Language Center and Foundation Year of Vietnamese-German University (VGU) in Vietnam and Country Director of WEAV (Women's Empowerment and Voice). Her research primarily focuses on women and leadership in academia, gender equality, global citizenship, women in STEM, and transnational higher education. She recently published a book chapter on Insights into Vietnamese Culture of Gender and Factors Hindering Academic Women's Advancement to Leadership Positions with Emerald Publishing Limited and an encyclopedia entry on Gender and Leadership with SAGE.

\section{References}

Ashwill, M. (2006). US institutions find fertile ground in Vietnam's expanding higher education market. International Higher Education, 44(Summer), 13-14. 
Bahous, R. N., Nabhani, M. B. \& Bacha, N. N. (2014). Code-switching in higher education in a multilingual environment: A Lebanese exploratory study. Language Awareness, 23(4), 353-368.

Bowen, G. A. (2009). Document analysis as a qualitative research method. Qualitative Research Journal, 9(2), 27-40. https://doi.org/10.3316/QRJ0902027

Cassidy, S. (2011). Self-regulated learning in higher education: Identifying key component processes. Studies in Higher Education, 3(8), 989-1000.

Charmaz, K. (2001). Grounded Theory. In R.M.Emerson (Ed.) Contemporary field research: Perspectives and formulations (pp. 335-352). Waveland Press.

Cromley, J. G., Perez, T. , \& Kaplan, A. (2016). Undergraduate STEM achievement and retention: Cognitive, motivational, and institutional factors and solutions. Policy Insights from the Behavioral and Brain Sciences, 3(1), 4-11.

Dao, K. V. (2015). Key challenges in the reform of governance, quality assurance, and finance in Vietnamese higher education-a case study. Studies in higher education, 40(5), 745-760.

Dewalt, K. M., \& DeWalt, B. R. (2002). Participant observation. Altamira Press.

Freeman, S. , Eddy, S. L., McDonough, M., Smith, M. K., Okoroafor, N.,Jordt, H., \& Wenderoth, M. P. (2014). Active learning increases student performance in science, engineering, and mathematics. Proceedings of the National Academy of Sciences, 111(23), 8410-8415.

Glesne, C. (2010). Becoming qualitative researchers: An introduction. Massachusetts: Pearson.

Gonzalez, H. B., and Kuenzi, J. J. (2012). Science, technology, engineering, and mathematics (STEM) education: A primer. Congressional Research Service, Library of Congress.

Guenther, K. M. (2009). The politics of names: Rethinking the methodological and ethical significance of naming people, organizations, and places. Qualitative Research, 9(4), 411-421.

Hwang, K. (2013). Effects of the language barrier on processes and performance of international scientific collaboration, collaborators' participation, organizational integrity, and interorganizational relationships. Science Communication, 35(1), 3-31.

Kvale, S. (1996). InterViews: An introduction to qualitative research interviewing. Sage Publications. Lin, X. (2019). Achievement Goal Orientations as Predictors of Self-Regulated Learning Strategies of International ESL Students. International Journal of Teaching and Learning in Higher Education, 31(2), 214-223.

Mazak, C. M., \& Herbas-Donoso, C. (2014). Translanguaging practices and language ideologies in Puerto Rican University science education. Critical Inquiry in Language Studies, 11(1), 27-49. 
Merriam, S. B., \& Tisdell, E. J. (2016). Qualitative research: A guide to design and implementation (4th ed.). Jossey-Bass.

Miles, M. B., Huberman, A. M, and Saldaña, J. (2014). Qualitative data analysis: A methods sourcebook. Sage Publications.

Nguyen, T. C., \& Dang, S. V. (2019). STEM education in Vietnam: Tools and methods. Electronic Paper of the Central Governmental Reasoning Council. Retrieved from http://hdll.vn/vi/thong-tin-lyluan/giao-duc-stem-tai-viet-nam-cong-cu-va-phuong-thuc.html

Nguyen, T. K. Q. (2011). Globalization and higher education in Vietnam. Journal of Interdisciplinary Studies, 23(1-2), 117.

Pintrich, P. R. (2000). The role of goal orientation in self-regulated learning. In M. Boekaerts, P.R. Pintrich, \& M. Zeiderner (Eds.). Handbook of self-regulation (pp. 451-502). Academic Press.

Rossman, G. B., \& Rallis, S. F. (2003). Learning in the field: An introduction to qualitative research. Sage Publications.

Saks, K., \& Leijen, Ä. (2014). Distinguishing self-directed and self-regulated learning and measuring them in the e-learning context. Procedia-Social and Behavioral Sciences, 112, 190-198.

Singer, B. D., \& Bashir, A. S. (1999). What are executive functions and self-regulation and what do they have to do with language-learning disorders? Language, Speech, and Hearing Services in Schools, $30(3), 265-273$.

Smith, M. K., Vinson, E. L., Smith, J. A. Lewin, J. D., \& Stetzer, M. R. (2014). A campus-wide study of STEM courses: New perspectives on teaching practices and perceptions. CBE-Life Sciences Education, 13(4), 624-635.

Stake, R. E. (1995). The art of case study research. Sage Publications.

Wilkins, S., \& Urbanovic, J. (2014). English as the lingua franca in transnational higher education: Motives and prospects of institutions that teach in languages other than English. Journal of International Education, 18(5), 405-425.

World Bank. (2017). Vietnam - New model university project : Restructuring (English). Washington, D.C.: World Bank Group. Retreived from http://documents.worldbank.org/curated/en/658091512074228528/Vietnam-New-ModelUniversity-Project-restructuring

Yao, C.W., \& Collins, C. (2018). Student-centered learning at a Vietnamese transnational university: Perspectives from Vietnamese graduate students. Journal of Further and Higher Education, 43(7), 959-974. 
Yao, C.W., Garcia, C.E., and Collins, C. (2019). English as lingua franca: Exploring the challenges and opportunities of English proficiency on Vietnamese graduate student learning. Journal for the Study of Postsecondary and Tertiary Education, 4, 209-229.

Yao, C.W., \& Garcia, C.E. (2018). International students in their own country: Motivation of Vietnamese graduate students to attend a collaborative transnational university. FIRE: Forum for International Research in Education, 4(2), 22-38.

Yao, C.W., \& Tuliao, M. (2019). Exploring Vietnamese graduate students' soft skill development for employability. Higher Education, Skills and Work-based Learning, 9(3), 250-263.

Zimmerman, B. J. (1989). A social cognitive view of self-regulated academic learning. Journal of Educational Psychology, 81(3), 329. 